\title{
Extent of Primary School Teachers' Utilization of Nature Corner as a Curriculum Resource for Effective Instruction
}

\author{
Olibie, Eyiuche Ifeoma (Phd) ${ }^{1}$
}

Adirika, Bakky Ngozi (Phd)2

Onyebuchi Geoffrey ${ }^{3}$

1, 2, 3 Department of Educational Foundations, Faculty of Education, Nnamdi Azikiwe University, Awka

Doi:10.5901/jesr.2015.v5n3p181

\section{Abstract}

A stratified random sample of 700 primary school teachers was surveyed to determine the extent of their utilization of nature corner as a curriculum resource for effective instruction. Three research questions and two hypotheses were formulated. Data was collected using a questionnaire and analyzed using mean scores and t-test. Findings revealed that the teachers most frequently given objectives for keeping nature corners were to meet supervision requirements and enhance environment beauty rather to exploit it to promote effective instruction. The nature corners kept comprised mainly of science and technology; arts and crafts; economics and commerce collections. School location and teachers' years of teaching experience did not affect effective use of nature corners in schools. The study concluded that primary school teachers did not highly utilize nature corner to promote effective learning. Hence, teachers should improve the utilization of nature corner as a curriculum resource for instruction, even in the face of more sophisticated resources.

Keywords: Instructional materials, curriculum resource, effective instruction, teaching and learning

\section{Introduction}

In recent discussions on the resources for effective teaching and learning, emphasis has been more on using modern learning resources such as computers, Internet, multimedia, language laboratories etc. This is necessary considering the fact that such modern curriculum resources can facilitate learning and open new frontiers of knowledge. What is not necessary is the overwhelming assumption that "with so much change in the learning resources landscape, there is a tendency to forget, discard, or even neglect older learning resources as out-dated, outmoded, inefficient and inadequate" (Hannon, 2000, p.35). Such assumption would be a waste of a wealth of valid resource because most of the older resources have been proved to be very effective and must remain effective over time.

One of such older resources that has been a prevalent feature of most primary schools in Anambra State is what is commonly referred to as Nature corner where local authentic materials and real objects from the environment are kept. Such authentic materials comprise mainly of pupils' collections of objects in their environments such as grains, shells, cans, bottles, skins etc. Vale \& Feunteun (1995) classified such nature corner collections into four broad categories namely:

- Language and Mathematical collections (e.g. Shapes, alphabets, measuring instrument)

- Arts and Crafts collections (e.g. Shells, carvings)

- Science and Technology collections (e.g. Grains, beans stalks)

- Economics and commerce collections (e.g. Shopping items)

Teachers are expected to improvise and use the materials from nature corners as curriculum resources to motivate pupils, sustain pupils' interest, and facilitate learning. Hence, it is deemed important in this study to investigate the extent to which primary school teachers utilize nature corner as a curriculum resource for effective instruction in Nigeria. 


\section{Literature Review}

Researchers have sought to document and understand differences in the ways teachers draw from materials to design instruction (Brown, 2009; Collopy, 2003; Lloyd, Remillard \& Herbel-Eisenmann, 2009; Olibie, Nwabunwanne \& Ezenwanne, 2013; Sherin \& Drake, 2009). The integration of such instructional materials in classroom practice is believed to bolster the quality of instruction by fostering student-centered pedagogies (Abdo \& Semela 2010; Burman \& Mutendwahothe, 201; Davis \& Krajcik, 2005). Furthermore, according to Mateer, Purdom and Porter (2012), the use of relevant instructional media as curriculum resources in the classroom is invaluable since they engage students, aid their retention of knowledge, motivate interest in the subject matter and help to illustrate the relevance of many concepts taught. It would also familiarize learners with much needed indigenous knowledge. The use of nature corner as a curriculum resource is imperative because Bates, Chiba, Kube, \& Nakashima, (2009) noted that the loss of pupils' specialised knowledge of nature is a grave concern for many indigenous communities throughout the world to the extent that commendable efforts are being made to better align educational curricula with indigenous realities and to incorporate local knowledge and language content into school curricula.

Studies such as Calderin (1994) and Olibie et al (2013) clearly established that when teachers make effective use of authentic indigenous materials as found in nature corners, pupils become highly motivated which results in improved class attendance and more completed projects and assignments. In addition pupils also become actively involved in their own learning, encouraging comprehension rather than mere memorization of facts (Elinvoki, 1996). Indigenous materials while reinforcing facts, present pupils with real life situations in which they learn about facts and ways of manipulating facts. According to Vale \& Feunteun (1995:37)

Nature corner provides a rich resource environment grounded in levels of processing theory and modes of learning. It provides not only a vivid and natural environment for the accumulation of facts of a language but also tools to synthesize and integrate new knowledge into existing knowledge.

It follows then that the prevalence of Nature corner in most primary schools is desirable and should be used as a curriculum resource aimed towards:

1. Supporting cognitive development in items of subject matter e.g. language, science \& technology, art \& craft, etc (Vale \& Feunteun, 1995)

2. Developing observational and discovery skills among pupils (Hannon, 2000)

3. Promoting awareness of the environment (Clark, 1996)

4. Promoting co-operative work and socialization (Calderin, 1994)

5. Supporting emotional needs in terms of providing a situation in which pupils will proudly display their works (Namuddu, 1990).

The principal impression that emerges from the fore-going discourse is that Nature corner has been an acknowledged curriculum resource for promoting effective instruction. Every teacher is expected to use Nature corner to facilitate instruction irrespective of the school location (urban or rural area) and teacher's years of teaching experience. To effectively do this, teachers ought to have objectives for keeping Nature corner, keep several collections in the Nature corners as well as utilize the collections to engage learners in various learning activities. It is therefore surprising that despite the prevalence of this resource in primary schools, resource-based learning has not been encouraged and effective instruction has not been promoted (Anya, 2001 \& Hannon, 2000). One begins to wonder whether primary school teachers are actually exploiting Nature corner as a resource for facilitating instruction. This question becomes more pertinent when one considers the fact that there is a tendency for teachers to neglect Nature corner in the face of modem technology. This neglect is more striking in that teachers readily admit that they experience considerable difficulty obtaining resources for instruction where as Nature corner lies quietly in a portion in their classroom. The purpose of this study was therefore to investigate the extent to which teachers utilize Nature corner as a curriculum resource for effective instruction.

\subsection{Research questions}

Three research questions guided this study:

1. What are the teacher's most commonly given objectives for keeping Nature corner in their classrooms?

2. What type of collections do teachers actually keep in the nature corner?

3. What type of activities do teachers exploit nature corner to engage pupils in? 


\subsection{Hypotheses}

Two null hypotheses were tested at the 0.05 level of significance

1. School location is not a significant factor affecting effective utilization of Nature corner as a curriculum resource for effective instruction.

2. Teacher's years of teaching experience is not a significant factor affecting effective utilize of nature corner as a curriculum resource for effective instruction.

\section{Method}

\subsection{Design and Area of the Study.}

A descriptive survey was carried out in primary schools in Onitsha Education zone of Anambra State.

\subsection{Population and Sample}

Stratified sampling was applied to a population of 2814 primary school teachers in Onitsha Education Zone of Anambra State. The stratification was based on location: urban and rural school, as well as years of teaching experience (0-5 years, more than 5 years). Thus, 30 urban schools and 30 rural schools were selected. From the selected schools, 320 teachers with 0-5 years of teaching experience and 350 teachers with more than 5 years teaching experience were proportionally selected. This brings the total sample size to 700 respondents. This sample represented approximately $25 \%$ of the population recommended by Gay (1996).

\subsection{Research Instrument}

The researchers constructed a survey questionnaire consisting of two sections. Section A requested information on the respondents' years of teaching experience, and the location of the school. Sections B included 15 items that were structured on a four - point Likert scale of strongly agree (4 pts), Agree (3 pts), Disagree (2 pts), and strongly disagree (1 pts). These items elicited information on the extent of the teacher's utilization of nature corner in classrooms.

\subsection{Validity and Reliability}

The instrument was face and content validated by three curriculum and instructional technology experts. Their criticisms and comments enhanced the structure and content of the final questionnaire. The test-re-test method was used in ascertaining the reliability of the instrument. The instrument was first administered to 50 teachers in Awka education zone. After 3 weeks, the instrument was administered again. A Pearson product moment correlation of the scores yielded a co-efficient of 0.92 , which was satisfactory for the study.

\subsection{Data Collection and Analysis}

Copies of the questionnaire were distributed with the help of the primary school teachers. Data Analysis was done using mean ratings and Ranking for the research questions and the T-test for the hypotheses. Results are presented in tables $1-5$

\section{Results and Discussions}

Table 1: Mean ratings and ranking of the teachers' most commonly given objectives for keeping nature corner.

\begin{tabular}{clccccc}
\hline Objectives & Urban & \multicolumn{2}{c}{ Rural } \\
\hline & & $\bar{X}$ & RANK & $\bar{X}$ & RANK & COMMENTS \\
\hline 1. & To beautify classrooms & 4.62 & $2^{\text {nd }}$ & 4.42 & $2^{\text {nd }}$ & SA \\
2. & To meet supervision requirements & 4.85 & $1^{\text {st }}$ & 4.82 & $1^{\text {st }}$ & SA \\
3. & To use as a resource for teaching and learning & 2.50 & $5^{\text {th }}$ & 2.62 & $5^{\text {th }}$ & D \\
4. & To display pupils' projects & 3.02 & $4^{\text {th }}$ & 4.40 & $3^{\text {rd }}$ & $\mathrm{A}$ \\
5. & To promote awareness of the environment & 3.73 & $3^{\text {rd }}$ & 3.68 & $4^{\text {th }}$ & $\mathrm{A}$ \\
\hline
\end{tabular}


Analysis in table 1 shows clearly that among the teachers' most commonly given objectives for keeping nature corner, item 2 ranked first. Item I followed this swiftly. While items 4 and 5 ranked differently based on the location of the school, item 3 ranked last for both respondents. This indicates that while the teachers' most common objectives for keeping nature corner is to meet supervision requirements, the least objective is to use it as a resource for effective instruction.

Table 2: Mean ratings and ranking of the type of collections teachers keep in their nature corners.

\begin{tabular}{lccccc}
\hline Objectives & \multicolumn{6}{c}{ Urban Teachers } & \multicolumn{2}{c}{ Rural Teachers } & \\
\cline { 2 - 6 } & $\bar{X}$ & RANK & $\bar{X}$ & RANK & COMMENTS \\
\hline Type of Collection & 2.68 & $4^{\text {th }}$ & 2.80 & $4^{\text {th }}$ & D \\
Language and Mathematical collections & 4.43 & $2^{\text {nd }}$ & 4.63 & $3^{\text {rd }}$ & SA \\
Science and Technoctlogy Collections & 4.00 & $3^{\text {rd }}$ & 4.83 & $1^{\text {st }}$ & SA \\
Commerce and Economics & 4.70 & $1^{\text {st }}$ & 4.65 & $2^{\text {nd }}$ & SA \\
None of the Above & 1.80 & $5^{\text {th }}$ & 1.90 & $5^{\text {th }}$ & SD \\
\hline
\end{tabular}

As can be seen from table 2, most of the respondents strongly agreed that they keep mostly science and technology collection, economic and commerce collections, as well as arts and crafts collections. Language and mathematical collections ranked among the least of the collections kept in the nature corner. Only few of the respondents indicated that they keep no collections at all.

Table 3: Mean ratings and ranking of the activities teachers exploit nature corner to engage pupils in.

\begin{tabular}{lccccc}
\hline Objectives & Urban & Rank & Rural & Teachers & \\
\cline { 2 - 6 } Activities & $X$ & RANK & $X^{\text {X }}$ & RANK & COMMENTS \\
\hline Drawing/Recording Tasks & 4.78 & $1^{\text {st }}$ & 4.81 & $1^{\text {st }}$ & SA \\
Explanation Tasks & 4.76 & $2^{\text {nd }}$ & 4.42 & $2^{\text {nd }}$ & SA \\
Observation Tasks & 3.00 & $3^{\text {rd }}$ & 2.34 & $3^{\text {rd }}$ & D \\
Participation Tasks & 2.46 & $4^{\text {th }}$ & 2.33 & $4^{\text {th }}$ & D \\
Communication Tasks & 2.41 & $5^{\text {th }}$ & 2.03 & $5^{\text {th }}$ & D \\
\hline
\end{tabular}

Table 3 reveals that teachers mostly used nature corner to engage students in drawing/recording tasks. Explanation tasks ranked $2^{\text {nd }}$ in the list observation, participation, and communication tasks ranked $3^{\text {rd }}, 4^{\text {th }}$ and $5^{\text {th }}$ respectively. Worse still, these three least ranking items did not obtain up to the acceptable mean of 3.00. This indicate that teachers engaged pupil more in drawing/recording tasks and explanation tasks to the negligence of observation, discovery, participation, and communication tasks.

Table 4: t-test comparison of the mean ratings of school location as a significant factor affecting teacher effective use of Nature corner as a curriculum resource.

\begin{tabular}{lccccccc}
\hline GROUP & N & X & SD & DF & T-CAL & T-CRIT & P \\
\hline Urban Primary School Teachers & 350 & 3.05 & 0.78 & \multirow{2}{*}{698} & \multirow{2}{*}{1.42} & \multirow{2}{*}{1.96} & \multirow{2}{*}{0.05} \\
Rural Primary Teachers & 350 & 3.00 & 0.76 & & & & \\
\hline
\end{tabular}

The calculated T value of 1.42 is less than the critical value of 1.96 at 0.05 level of significance (DF=698) as revealed in Table 4. This decision is therefore to accept the null hypothesis. Thus, school location is not a significant factor affecting teachers' effective use of Nature corner as a curriculum resource.

Table 5: t-test comparison of the mean ratings of teaching experience as a significant factor affecting teachers effective use of Nature corner as a curriculum resource.

\begin{tabular}{lccccccc}
\hline GROUP & N & X & SD & DF & T-CAL & T-CRIT & P \\
\hline 05 Years & 320 & 3.02 & 0.78 & & & & \\
5 Years and Above & 380 & 3.41 & 0.82 & 698 & 1.72 & 1.96 & 0.05 \\
\hline
\end{tabular}

Analysis in table 5 indicates that the t-cal of 1.72 is less than the t-crit of 1.96 . The null hypothesis is not rejected. The 
conclusion is that years of experience is not a significant factor affecting teachers' use of nature corner as a curriculum resource.

\section{Discussion and Implication of Findings}

Analysis of response for research question 1 (table 1) shows that the most common objective given by teachers for keeping nature corner in schools is for the teachers to meet with supervision requirement and beautify the classrooms. Some of the teachers admit that they keep nature corner for the display of pupils' projects and promote awareness of the environment. Unfortunately, only a few teachers admit that they use nature corner as a resource for effective instruction, this finding is in line with Clark (1996) who reported that some teachers keep collections of authentic materials because the school administration demands such. Consistent with the notions of Nammudu (1990) and Elinvoki (1995), this study establishes that nature corner is also used for the display of pupils project and promote awareness of the environment. The implication of this finding is that although teachers keep nature corner for supervision, environmental and project reasons, they fail to use the resources in the nature corner to support learning. The validity of such an exercise is extremely doubtful when one considers the wide range of experience that the resources in the nature corner can be used to reinforce in learners.

The study further reveals that most teachers strongly agree that they keep science and technology collections, commerce and economic collections as well as arts and crafts collections. This must be seen as modest gain as it will encourage pupils to be productive. However, the idea of neglecting mathematical and language collections as revealed in this study is undesirable. It is true that any collection in the nature corner can be used to foster language learning, but in the light of the need to provide a balanced curriculum for every pupil (Vale \& Feuteun, 1995), more is required. Teachers need to strive towards adding a variety of collection for a variety of subjects in their nature corner. This will demonstrate the diversification of curriculum required for effective learning (Mkpa, 2002). This finding agrees with Vale \& Feuteun (1995), who observed that most elementary school keep science, technology, arts, and shopping collection in their class rooms but neglect other areas such as maths, hygiene, music and worse still language.

Drawing/recording and explanatory tasks ranked the $1^{\text {st }}$ two major activities that teachers use nature corners to engage students in. Although observation tasks scored up to the acceptable mean rating for the urban teachers, it scored less for the rural teachers. Participation and communication tasks were ranked as the least. Agreed that drawing/recording and explanation tasks are indispensable in classrooms, they cannot work effectively in isolation of observation, participation and communication tasks (Clark, 1996). This finding implies that there is a tendency for teachers to neglect activities that support cognitive development in favor of more and more productive tasks dependent upon already made art facts. There is also a tendency to downgrade the role of observation and of participation tasks. This further implies that teachers may be spending most of classroom time on teacher- centered rather than real discussion that spur pupils to communicate. Thus pupils bring these collections to their classroom as projects, which are seldom if ever discussed or observed in terms of their other knowledge values. It is not surprising therefore that pupils never learn or retain what occurs in the course of these projects. In line with this study, Olibie et al (2013) observed that teachers find a sense of achievement in keeping pupils busy with projects, with little questioning as to whether the experience provided have led to increased language learning.

Finally, this study established that school location and years of teaching experience are not significant factors that affect the effective use of nature corner as a resource for effective instruction. This implies that both urban and rural primary school teachers do not make effective use of Nature corner as a curriculum resource.

\section{Conclusion}

The prevalence of nature corner in most primary schools in Onitsha zone provides an ever-widening array of resources for effective instruction. It is clear, however that there are still glaring areas of weakness and negligence as regards its use. Teachers have understandably been more concerned with keeping nature corners in order to maintain supervision requirements and enhance environmental beauty and awareness than to exploit it to promote effective instruction. Few teachers have managed yet to break through age long traditions of drawing/recording and teacher-based explanation towards using nature corner to foster discovery, observation, participation and communication skills in learners. Thus, the potential of nature corner as an effective curriculum resource for effective learning has not been fully utilized to a point where effective learning can readily take place. 


\section{Recommendations}

1. Government school administrations and teachers should encourage the utilization of Nature corner in schools despite the availability of modem education technology facilities.

2. Teachers should strive to give pupils worthwhile projects based on resources in the Nature corners and must give pupils opportunity to discover, observe, and communicate the basic content of the projects.

3. Teachers' objectives for keeping Nature corners should always be more focused on facilitating teaching and learning.

4. Where objective have been clearly set, teachers must discuss openly each learning resource in nature corners, while it is included, while it is important and what constraints prevail. This will enable teachers and pupil to work better in an environment where pupil confident is promoted through participation tasks. Better still, teachers and pupils must plan towards the collections to be included in the nature corner, the goals, the assignments and tasks to be performed. This way, nature corner is exploited, modeled, made, promoted or dramatized, by both the teacher and pupils.

\section{References}

Abdo, M. \& Semela, T. (2010). Teachers of poor communities: The tale of instructional media use in primary schools of Gedeo zone, Southern Ethiopia. Australian Journal of Teacher Education, 35 35(7). http://dx.doi.org/10.14221/ajte.2010v35n7.7.

Anya, O.A (2001, July), Managing the myths of the Nigerian reality. This Day. 7:2246 (34-35).

Bates P., Chiba, M., Kube, S. and Nakashima, D. (2009) Learning and Knowing in Indigenous Societies Today. UNESCO: Paris

Brown, M. (2009). The teacher-tool relationship: Theorizing the design and use of curriculum materials. In J. T. Remillard, B. HerbelEisenmann, \& G. Lloyd (Eds.), Mathematics teachers at work: Connecting curriculum materials and classroom instruction (pp. 17-36). New York: Routledge

Burman, M. S. \& Mutendwahothe, W. L. (2013). Improvisation and the use of community resources in business studies teaching. Journal of Social Science, 34(1): 1-7

Calderin, S.J (1994). Effect of interactive multimedia on students' achievement of curriculum objective, media and methods. 28 (3), 1214.

Clark, J.C. (1996). Curriculum renewal in schools foreign language learning Oxford: Oxford University Press.

Collopy, R. (2003). Curriculum materials as a professional development tool: How amathematics textbook affected two teachers' learning. The Elementary School Journal,103 (3), 287-311.

Davis, E., \& Krajcik, J. (2005). Designing educative materials to promote teacher learning. Educational Researcher, 34 (3), 3-14

Elinvoki, M.I. (1995). Traditional resources for language instruction. Columbia: FUNDAEC.

Gay, L.R. (1996). Educational research: Competencies for analysis and application (5th Edition) New York: Merill

Hannon, $\mathrm{P}$ (2002). Reflecting on literacy in education. London: Pergamon Press.

Lloyd, G., Remillard, J. T., \& Herbel-Eisenmann, B. (2009). Teachers' use of curriculummaterials: An emerging field. In J. T. Remillard, B. Herbel-Eisenmann, \& G. Lloyd(Eds.), Mathematics teachers at work: Connecting curriculum materials and classroom instruction (pp. 3-14). New York: Routledge

Mateer, D., Purdom, R., Ghent, L., \& Porter, T. (2012). Using media to enhance teaching and learning. Retrieved from SERC Portal for Educators.

Mkpa. M.A. (2002, September). Curriculum diversification as a basic for entrepreneurship. lead paper presented at the $15^{\text {th }}$ annual conference of the Curriculum Organization Of Nigeria Held At A.I.C.E. Owerri Sept. 20-22.

Nakashima, D., Prott, L. \& Bridgewater, P. (2000) Tapping into the worldâ€的s wisdom, UNESCO Sources, 125, July-August, p. 12.

Namuddu, K (1990). MINDSACROSS: A schools community integrated system for living literacy: Case study of Uganda primary schools. Kampala: Carlos Cannon

Olibie, E. I., Nwabunwanne, C \& Ezenwanne, D. N (2013): Teachers' improvisation of instructional materials for Nigerian home economics curriculum delivery: challenges and Improvement strategies. International Journal of Adult Vocational Education and Technology. 4(4) 74-83. doi>10.4018/ijavet.2013100105

Philips, M (1995). Resource in English language instruction. The America Educator 3(7) 16-19

Vale, D \& Feunteun, A (1995). Teaching children English: A training course for teachers of English for children. Cambridge: University Press. 